\title{
Influência da Epoca de Semeadura sôbre o Rendimento do Rabanete (")
}

\author{
Salim Simão \\ Escola Superior de Agricultura «Luiz de Queiroz»
}

(*) Recebido para publicação em 31-10-1960. 


\section{INTRODUÇÃO}

O rabanete, Raphanus sativus, L., da familia das cruciferae é dentre as hortaliças o de ciclo mais rápido; completando o seu desenvolvimento em um periodo de aproximadamente 25 dias. Sua exploração é indicada como cultura intercalar junto às outras plantas de crescimento mais lento. Knott (1930) diz que os rabainetes preferem solos frescos e úmidos durante o verão e outono e quentes durante a primavera e inverno.

Com o intuito de se conhecer o comportamento do rabanete durante todos os meses do ano, iniciamos o presente estudo.

\section{MATERIAL E MÉTODO}

Observações sôbre o desenvolvimento do rabanete foram feitas durante dois anos, 1952 e 1953, na Horta da Seç̧ão Técnica de Horticultura, da Escola Superior de Agricultura "Luiz de Queiroz".

A variedacte utilizada foi Redondo de Ponta Branca, e as semeaduras foram feitas em canteiros com 1,50 x 20,00 metros. $O$ espaçamento utilizado foi de 0,20 metros entre linhas e nas linhas após o desbaste de $0,05 \mathrm{~m}$.

Os canteiros receberam 5 quilos de matéria orgânica por metro quadrado e 100 gramlas de uma mistura mineral 6-10-6. O ciclo vegetativo foi de 25 dias. Colheram-se e pesaram-se 100 rabanetes de cada parcela. Foram feitas 4 repetições em cada ćpoca de semeadura.

\section{RESULTADOS E DISCUSSÃO}

Apresentamos, a seguir, no quadro I e II, os pêsos das raizes e fôlhas dos rabanetes colhidos em 1952 e 1953. 


\section{Influência da Epoca de Semeadura sôbre o Rendimento do Rabanete 257}
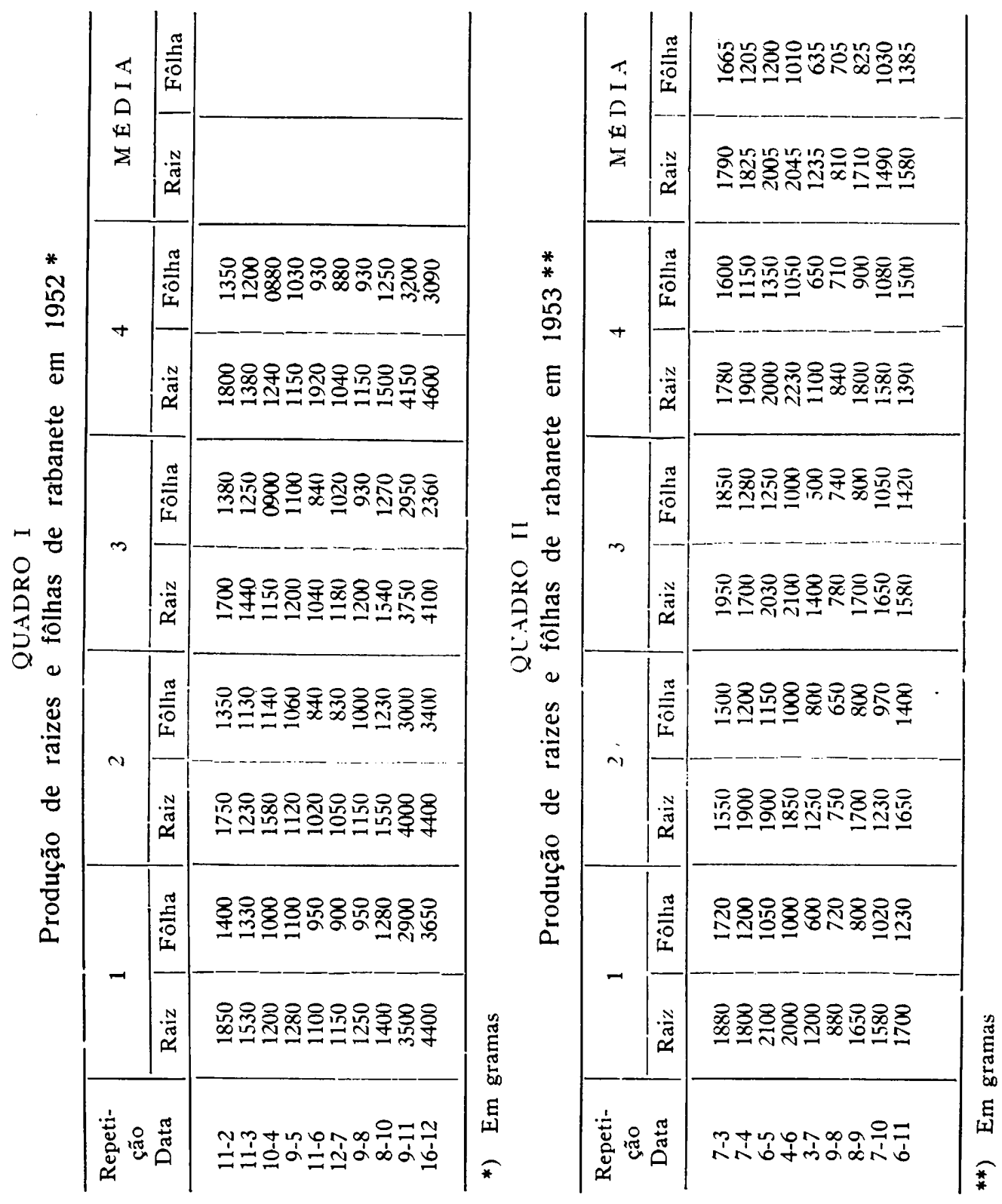
Apresentamos no Quadro III e IV a análise de variância das produções de raizes e fôlhas, em 1952 e nos Quadros V e VI as do ano de 1953.

\section{QUADRO III}

Análise de variância das raizes em 1952

\begin{tabular}{l|r|r|c}
\hline $\begin{array}{c}\text { Causa da } \\
\text { variação }\end{array}$ & G...I. & S.Q. & Q.M. \\
\hline Repetição & 3 & 30.540 & \\
Meses & 9 & 23.013 .960 & $2.557 .106^{* *}$ \\
Resíduo & 27 & 561.260 & \\
\hline
\end{tabular}

As médias de tratamentos tôdas com êrro padrão de $72 \mathrm{~g}$ são dadas abaixo :

\begin{tabular}{|c|c|c|}
\hline $6 / 12$ & & $3.375 \mathrm{~g}$ \\
\hline $9 / 11$ & . & $2.850 "$ \\
\hline $11 / 2$ & & $1.775 "$ \\
\hline $8 / 10$ & & $1.497 "$ \\
\hline $11 / 3$ & & $1.395 "$ \\
\hline $11 / 4$ & . & $1.292 "$ \\
\hline $9 / 8$ & & $1.187 "$ \\
\hline $10 / 5$ & . & $1.167 "$ \\
\hline $12 / 7$ & & $1.105 "$ \\
\hline $11 / 6$ & $\ldots$ & $1.045 "$ \\
\hline
\end{tabular}

A diferença mínima significativa ao nivel de $5 \%$ de probabilidade calculada pelo teste de Tukey, foi de $352,80 \mathrm{~g}$. Por esta média podemos dizer que a primeira média (dezembro) difere de todas as outras médias. A menor produção registrada foi em junho, porém, estatisticamente nos difere da de março para baixo. 
Influência dla Epoca de Semeadura sôbre o Rendimento do Rabanete 259

QUADRO IV

Análise da variância das fôlhas em 1952

\begin{tabular}{l|r|r|c}
\hline $\begin{array}{c}\text { Causa da } \\
\text { variação }\end{array}$ & (i..L. & S.Q. & Q.M. \\
\hline Repetição & 3 & 28.848 & \\
Meses & 9 & 8.915 .053 & 990.561 \\
Residuo & 27 & 416.677 & \\
\hline
\end{tabular}

As médias de tratamentos tôdas com êrro padrão de $62 \mathrm{~g}$ são dadas abaixo :
$6 / 12$
$9 / 11$
$2.375 \mathrm{~g}$
$11 / 2$
2.012 "
$8 / 10$
1. $370 "$
$11 / 3$
1. $257 "$
$10 / 5$
$1.227 "$
$11 / 3$
1.072
$9 / 8$
1.045
$12 / 7$
962
$11 / 6$
907 ".
887

A diferença minima significativa ao nivel de $5 \%$ de probabilidade calculada pelo teste de Tukey, foi de $304 \mathrm{~g}$. Por esta média podemos dizer que a primeira média difere de tôdas as outras médias, ocorrendo a maior produção em fôlhas em dezembro e a menor em junho, porém estatìsticamente não difere da produção de maio para baixo.

QUADRO $V$

Análise de variância das raizes em 1953

\begin{tabular}{l|r|r|r}
\hline $\begin{array}{c}\text { Causa da } \\
\text { variação }\end{array}$ & G... & S.Q. & Q.M. \\
\hline Repetição & 3 & 78.764 & \\
Meses & 8 & 4.903 .989 & $612.998^{* *}$ \\
Residuo & 24 & 658.535 & \\
\hline
\end{tabular}


As médias de tratamentos tôdas com êrro padrão de $83 \mathrm{~kg}$ são dadas abaixo :

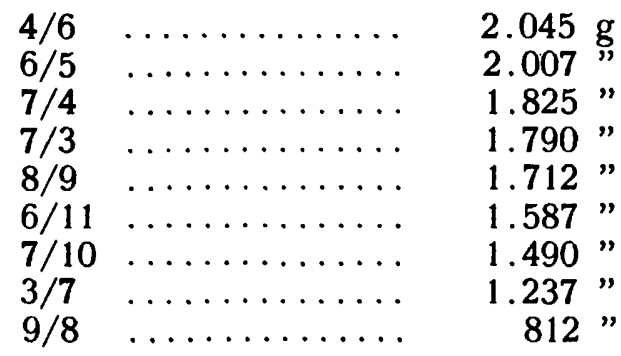

A diferença mínima significativa ao nivel de $5 \%$ de probabilidade calculada pelo teste de Tukey, foi de $400 \mathrm{~g}$. Observa-se pelos dados que as produções das 5 primeiras médias não diferem entre si e que as duas primeiras são diferentes da de novembro e as que a seguem. $\Lambda$ menor produção registrada ocorreu em agôsto e a maior em junho.

QUADRO VI

Análise da variância das fôlhas em 1953

\begin{tabular}{l|r|r|c}
\hline $\begin{array}{c}\text { Causa da } \\
\text { variação }\end{array}$ & G...L. & S.Q. & Q.M. \\
\hline Repetição & 3 & 32.050 & \\
Meses & 8 & 3.379 .644 & $422.445^{* *}$ \\
Resíduo & 24 & 334.956 & \\
\hline
\end{tabular}

As médias de tratamentos tôdas com êrro padrão de $59 \mathrm{~g}$ são dadas abaixo :

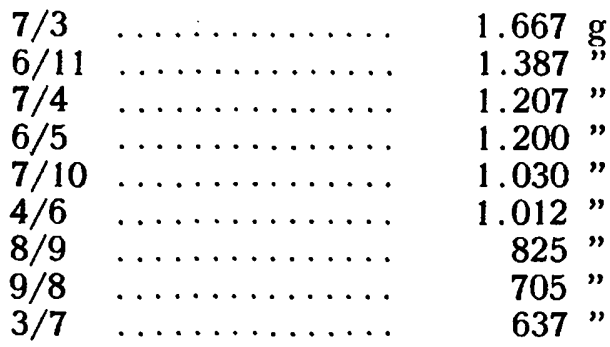


A diferença mínima significativa ao nível de $5 \%$ de probabilidade calculada pelo teste de Tukey, foi de $283,8 \mathrm{~g}$, mostrando que a produção de março e junho não diferem entre si, porém a de março supera tôdas as demais. A de novembro supera tôdas a partir de outubro. A menor produção de fôlhas ocorreu em julho, porém estatìsticamente só difere das médias de junho para cima.

Os dados das análise de variância do pêso das raizes em 1952 mostram que à medida que a temperatura abaixava houve uma redução no pêso, o mesmo se dando com relação às fôlhas.

Em 1953, tal fenômeno não se verificou, pois em junho dêste ano a produção superou as de novembro e dezembro do ano anterior, quando naquele ano tinha se apresentado como o mês menos produtivo.

As folhas que em 1952 tinham seguido de perto o pêso das raizes, em 1953 mostraram variações, e não exibiram correlação com o pêso das raizes.

Em 1952 a queda de rendimento pode ser explicada pelo abaixamento da temperatura de abril a agôsto, mas em 1953, apenas julho e agôsto produziram menos, coincidindo justamente com o periodo mais frio, e a produção de junho superou a de novembro, em algumas gramas, porém não foi diferente das produções de maio até setembro. Verificou-se que a partir de outubro as produções mostram nitidamente tendência a se elevarem.

No Gráfico I, poder-se-á apreciar o comportamento do rabanete durante os 2 anos. Verificou-se que em 1952 as fôlhas acompanharam paralelamente o pêso das raizes, em 1953 as fôlhas aproximaram-se da curva de 1952. Quanto ao pêso das raizes em 1953, houve um acréscimo gradativo até junho, decrescendo para agôsto e para novamente ascender de outubro em diante.

Pelos resultados obtidos verifica-se que o rabanete se desenvolve bem durante o ano todo, porém, sente os efeitos das temperaturas muito baixas.

\section{CONCLUSÕES}

Pelos resultados obtidos pode se concluir :

1 - $\mathrm{O}$ rabanete se desenvolve ràpidamente durante os períodos quentes e úmidos e ressentem-se com as baixas temperaturas.

2 - Os rabanetes podem ser considerados plantas de verão 
conquanto produzem bem durante os periodos de temperatura amena.

3 - A produção de fôlhas segue a de raizes, correspondendo de 20 a $40 \%$ do pêso da planta.

\section{SUMMARY}

During 1952 and 1953 the author observed that radish, Raphanus sativus, L, developed rapidily in the warmer and damper period of the year and endured the lower temperatures. The yiel of leaves counted from 20 to $40 \%$ of the plant weigth.

\section{LITERATURA CITADA}

KNO'1\%, J. E. - 1930 - Vegetable Growing - London, Henry Kinopton - 352 págs. 

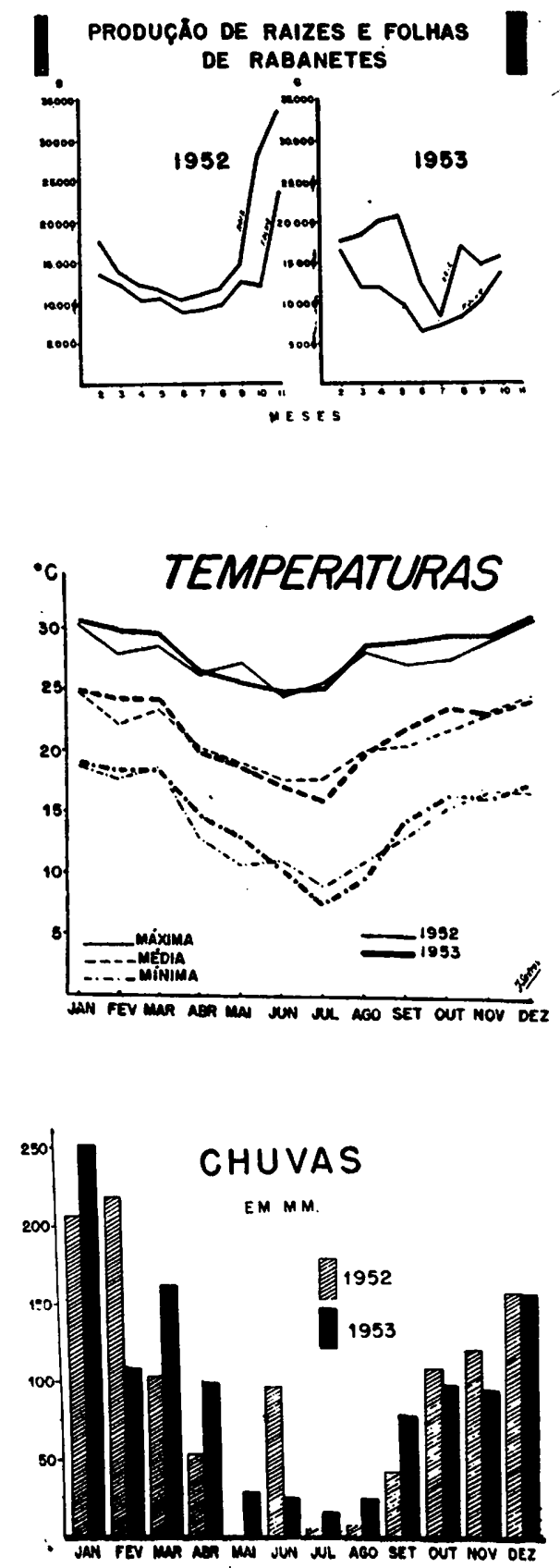
